\title{
TINGKAT DAN SEBARAN RISIKO BENCANA TANAH LONGSOR DI KECAMATAN WINDUSARI KABUPATEN MAGELANG
}

\author{
Oleh: \\ Akalili Zafirah Syarafina', Dyah Respati Suryo Sumunar², Nurul Khotimah² \\ ${ }^{1}$ Staff Pengajar SMAN 1 Kota Mungkid Kabupaten Magelang \\ 2Jurusan Pendidikan Geografi Fakultas Ilmu Sosial UNY \\ akalilisyarafina@gmail.com
}

\begin{abstract}
Abstrak
Penelitian ini bertujuan mengetahui: tingkat dan sebaran risiko bencana tanah longsor di Kecamatan Windusari. Populasi dalam penelitian ini terdiri atas populasi fisik yaitu seluruh unit lahan dan populasi non-fisik yaitu seluruh kepala keluarga di kecamatan Windusari yang berjumlah 10.642. Metode pengumpulan data yang digunakan adalah wawancara, observasi, dan dokumentasi. Analisis data menggunakan scoring, overlay, dan analisis deskriptif. Hasil penelitian: Tingkat risiko bencana tanah longsor di Kecamatan Windusari terdiri dari tingkat rendah (51,91\%), sedang (29,93\%), dan tinggi (18,16\%). Tingkat risiko rendah meliputi wilayah seluas 3.200 ha tersebar di Desa Dampit, Tanjungsari, Banjarsari, Bandarsedayu, Candisari, Genito, Gunungsari, Mangunsari, Semen, dan Gondangrejo. Tingkat risiko sedang meliputi wilayah seluas 1.845 ha tersebar di Desa Pasangsari, Wonoroto, Girimulyo, Ngemplak, Kalijoso, Kentengsari dan Umbulsari. Sedangkan tingkat risiko tinggi meliputi wilayah seluas 1.120 ha tersebar di Desa Kembangkuning, Balesari dan Windusari. Risiko bencana ditentukan oleh faktor bahaya, kerentanan, dan kapasitas. Faktor bahaya di Kecamatan Windusari sebagian besar (47\%) termasuk dalam kategori sedang, kerentanan sebagian besar $(55,52 \%)$ termasuk kategori tinggi, dan Kapasitas sebagian besar (56,87\%) termasuk kategori rendah.
\end{abstract}

Kata Kunci: Risiko, Tanah Longsor, Kecamatan Windusari

\begin{abstract}
This research aims at investigating: the level and distribution of landslide risks in Windusari District. The population in this research consists of physical population which includes all unit of land and non-physical population i.e. all head of family in Windusari sub-district or 10,642 family heads. Data collection techniques were interviews, observations, and documentations. The data were analyzed using scoring, overlay, and descriptive analysis. The results are: the risk level of landslide disaster in Windusari District consists of low (51.91\%), medium (29.93\%), and high (18.16\%) level. Low risk level covers an area of 3200 ha which spreads in Dampit, Tanjungsari, Banjarsari, Bandarsedayu, Candisari, Genito, Gunungsari, Mangunsari, Semen, and Gondangrejo Village. Medium risk level includes an area of 1845 ha which spreads in the village of Pasangsari, Wonoroto, Girimulyo, Ngemplak, Kalijoso, Kentengsari and Umbulsari. Meanwhile, the level of high risk covers an area of 1120 ha which spreads in the Village of Kembangkuning, Balesari and Windusari. Disaster risk is determined by using hazard, vulnerability, and coping capacity factors. Hazard factors in Windusari District are mostly (47\%) in the medium category, vulnerable are mostly (55.52\%) in the high category, and coping capacity are mostly $(56.87 \%)$ in low category.
\end{abstract}

Keywords: Risk, Landslide, Windusari Subdistrict 


\section{PENDAHULUAN}

Tanah longsor dapat terjadi di seluruh wilayah di Indonesia yang terletak pada bentuklahan asal proses penelanjangan atau disebut dengan bentuklahan denudasional. Bentuklahan asal proses denudasional dapat dijumpai di hampir seluruh pulau di Indonesia dengan ciri-ciri relief sangat kasar, terjadi pendalaman lembah, dan bentuk-bentuk struktural tidak lagi nampak jelas. Bentuklahan asal proses denudasional terdiri dari prosesproses pelapukan (weathering), gerakan massa (mass movement), dan pengendapan (sedimentation). Hardiyatmo (2006:15), menjelaskan bahwa tanah longsor merupakan salah satu tipe gerakan massa tanah yang besar di sepanjang bidang longsor kritisnya. Gerakan massa tanah ini merupakan gerakan ke arah bawah material pembentuk lereng, yang dapat berupa tanah, batu, timbunan batuan atau campuran material lain. Proses terjadinya gerakan massa melibatkan interaksi yang kompleks antara aspek geologi, geomorfologi, hidrologi, curah hujan, dan tata guna lahan.

Dampak dari kejadian tanah longsor yang terjadi dapat menimbulkan berbagai kerusakan dengan berbagai tingkatan. Kerusakan yang ditimbulkan dari bencana tanah longsor dari segi fisik dan lingkungan diantaranya berupa kerusakan lahan area pertanian dan peternakan, kerusakan area pemukiman dan fasilitas umum, jatuhnya korban luka maupun korban jiwa. Dampak dari bencana tanah longsor dari segi sosial dan ekonomi adalah menyebabkan terganggunya aktivitas kehidupan manusia (sekolah, bekerja, harus mengungsi dan sebagainya), aktivitas perekonomian menjadi lumpuh serta menimbulkan kerugian harta benda.

Provinsi Jawa Tengah memiliki catatan panjang terhadap kejadian bencana tanah longsor. Pada tanggal 12 Desember 2014 bencana tanah longsor menimpa masyarakat Kecamatan Karangkobar, Kabupaten Banjarnegara, yang merupakan bencana tanah longsor terparah selama tahun 2014. Kejadian ini berdampak pada jatuhya korban meninggal dunia sebanyak 93 jiwa dan lebih dari 150 unit rumah warga tertimbun material longsor. Mengacu kepada batasan geomorfologi, wilayah tengah Jawa Tengah secara geomorfologis termasuk dalam kompleks Pegunungan Serayu Selatan. Pegunungan Serayu Selatan merupakan zone yang mengalami pelipatan hebat dan dorongan selama miosen. Pegunungan Serayu Selatan bagian timur berbatasan dengan dataran vulkanik Gunung Sumbing yang merupakan bagian dari depresi sentral Jawa Timur (Bemmelen, 1949: 29). Kondisi geomorfologis ini berpengaruh terhadap tingginya potensi bencana tanah longsor.

Gunung Sumbing merupakan tipe gunungapi strato yang diketahui terakhir meletus pada tahun 1730, dengan puncaknya yang berada pada ketinggian 3371 meter di atas permukaan laut atau mdpl (http://volcano.si.edu//). Gunung Sumbing secara administratif terletak di tiga kabupaten di Jawa Tengah, yaitu Kabupaten Magelang, Kabupaten Temanggung dan Kabupaten Wonosobo. Selain kerucut strato, morfologi lereng Gunung Sumbing juga ditandai dengan adanya kerucut parasiter. Kerucut Parasiter (parasitic cone type) merupakan tipe perbukitan atau gunungapi yang pembentukannya berkaitan langsung dengan dengan kegiatan gunung api (M. Alzar et al, 1988 : 151). Gunung Sumbing merupakan salah satu wilayah di Jawa Tengah yang memiliki potensi bencana tanah longsor selain di wilayah Pegunungan Serayu Selatan. 
Kecamatan Windusari merupakan salah satu kecamatan di Kabupaten Magelang yang terletak di kaki Gunung Sumbing bagian tenggara. Kecamatan Windusari juga merupakan salah satu daerah yang paling rawan terhadap bencana tanah longsor di Kabupaten Magelang setelah Kecamatan Kaliangkrik, berdasarkan Peta Ancaman Bencana Tanah Longsor Kabupaten Magelang Tahun 2014. Kecamatan Windusari berada pada ketinggian 400 hingga 3200 mdpl, selain memiliki relief yang terjal Kecamatan Windusari juga memiliki potensi bahaya alam yang tinggi, salah satunya tanah longsor.

Data kejadian longsor terbaru di Kecamatan Windusari yakni pada tanggal 24 Desember 2015, di Dusun Campurejo, Desa Kembangkuning, tepatnya pada koordinat $110^{\circ} 10^{\prime 2} 27^{\prime \prime} B T$ dan $7^{\circ} 25^{\prime} 34^{\prime \prime} \mathrm{LS}$ di ketinggian 638 mdpal serta pada koordinat $110^{\circ} 10^{\prime} 13^{\prime \prime} \mathrm{BT}$ dan $7^{\circ} 25^{\prime} 32^{\prime \prime}$ LS di ketinggian 625 mdpal. Dampak yang ditimbulkan dari dua kejadian longsor ini adalah tertutupnya akses jalan yang merupakan jalan lokal yang menuju Candi Selogriyo. Titik longsor pertama merupakan longsor yang terjadi pada perbukitan yang menimbun area persawahan warga sedangkan pada titik longsor yang kedua merupakan longsor yang terjadi pada area sawah yang menimbun area sawah.

Dari segi demografis, Kecamatan Windusari memiliki populasi penduduk sebanyak 48.707 jiwa (BPS, 2015). Tingginya jumlah penduduk dan besarnya angka ketergantungan di Kecamatan Windusari dapat meningkatkan tingkat kerentanan terhadap bencana tanah longsor. Dengan adanya potensi bencana tanah longsor di Kecamatan Windusari serta disisi lain terdapat penduduk yang cukup banyak berada di daerah rawan bencana tanah longsor, dimungkinkan wilayah ini senantiasa menghadapi risiko bencana tanah longsor pada masa mendatang. Untuk mengurangi risiko bencana perlu dilakukan analisis mengenai tingkat dan sebaran risiko bencana tanah longsor. Analisis risiko dapat dimanfaatkan sebagai salah satu referensi dalam kegiatan manajemen bencana. Hal ini sangat bermanfaat untuk mengurangi risiko bencana pada masa mendatang walaupun potensi longsor tetap ada di wilayah ini, sebagai akibat berlangsungnya proses denudasi yang secara alami terjadi oleh pengaruh iklim terhadap morfologi kerucut Gunung Sumbing

\section{METODE}

Penelitian ini merupakan penelitian deskriptif kuantitatif, penelitian deskriptif berarti penelitian yang bertujuan untuk mengungkap suatu masalah atau keadaan sebagaimana adanya, sedangkan metode kuantitatif berarti suatu metode yang digunakan untuk makna yang terkandung di balik angka. Penelitian ini menggunakan analisis skor (scoring) dan pembobotan terhadap hasil pengumpulan data lapangan (hasil wawancara, observasi dan dokumentasi). Populasi dalam penelitian ini terdiri atas: (1) populasi fisik adalah seluruh unit lahan di Kecamatan Windusari, (2) populasi non-fisik adalah seluruh kepala keluarga di kecamatan Windusari yang berjumlah 10.642 kepala keluarga. Penentuan sampel untuk populasi non-fisik dilakukan dengan menggunakan metode proportional random sampling atau sampel secara acak berimbang. Variabel dalam penelitian ini terdiri atas variabel: (1) bahaya, (2) kerentanan, dan (3) kapasitas. Pengambilan kesimpulan dalam penelitian ini didasarkan pada angka-angka hasil perhitungan yang menggunakan beberapa rumus dasar sehingga diperoleh kesimpulan yang bersifat kuantitatif. 


\section{HASIL DAN PEMBAHASAN}

\section{Daerah Penelitian}

Kecamatan Windusari merupakan salah satu kecamatan yang terletak di sebelah barat laut wilayah Kabupaten Magelang. Secara astronomis Kecamatan Windusari berada diatara $110^{\circ} 4^{\prime} 37^{\prime \prime}$ BT $-110^{\circ} 13^{\prime} 0^{\prime \prime}$ BT dan $7^{\circ} 22^{\prime} 50^{\prime \prime}$ LS - $7^{0} 26^{\prime} 55^{\prime \prime}$ LS. Wilayah ini dibatasi pada sisi utara oleh Kabupaten Temanggung, sebelah timur berbatasan dengan Kecamatan Secang, sebelah selatan berbatasan dengan Kecamatan Bandongan, dan sebelah barat berbatasan dengan Kecamatan Kaliangkrik (Gambar 1). Kecamatan Windusari memiliki luas wilayah 6.165 ha dengan rata-rata luas wilayah setiap desa 308,5 ha. Tipe iklim Kecamatan Windusari berdasarkan klasifikasi Schmidt-Ferguson dengan menggunakan data curah hujan selama periode 10 tahun adalah tipe curah hujan $C$ yaitu agak basah.

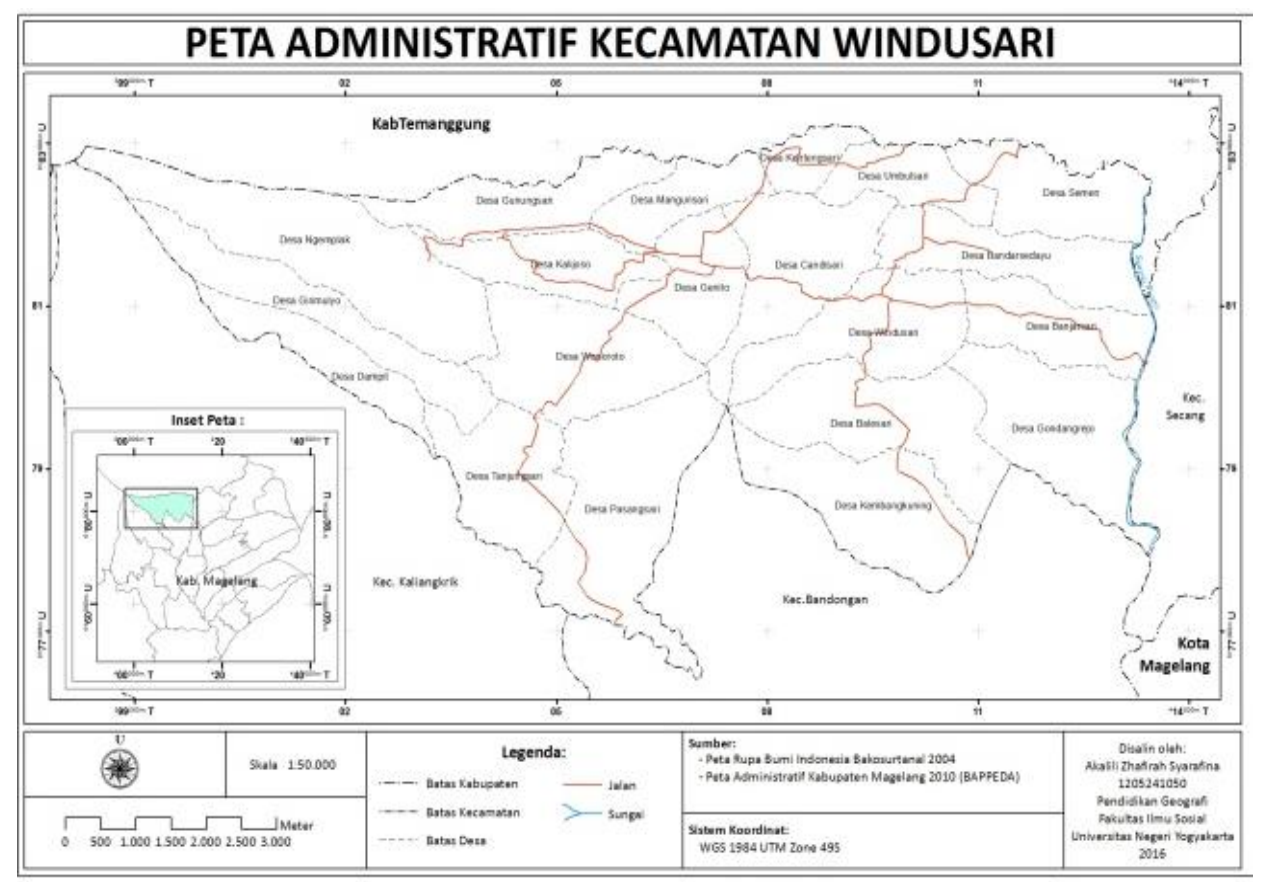

Gambar 1. Peta Administratif Kecamatan Windusari

Wilayah Kecamatan Windusari secara fisik merupakan bagian dari Gunungapi Sumbing. Menurut Peta Geologi Lembar Magelang dan Semarang, yang dibuat oleh RE. Thanden, et al., pada tahun 1996 dengan skala 1:100.000 diketahui bahwa kondisi geologis daerah penelitian terdiri dari Qls (Lava Gunungapi Sumbing), Qsm (Batuan Gunungapi Sumbing), Qke (Batuan Gunungapi Kekep), Qct (Tuf Kristal), Qgi (Batuan Gunungapi Gianti), dan Qpl (Porfir dan Lahar).

Kecamatan Windusari memiliki variasi tingkat kemiringan lereng dari kriteria datar sampai kriteria sangat terjal dan memiliki variasi ketinggian wilayah mulai dari kriteria perbukitan hingga kriteria pegunungan berdasarkan peta kemiringan lereng dan peta ketinggian tempat yang diterbitkan oleh BAPPEDA Kabupaten Magelang tahun 2010. Kecamatan Windusari secara geomorfologis terletak pada zona tengah Pulau Jawa yang juga merupakan bagian dari wilayah Gunungapi Sumbing yang secara geomorfologis 
terdiri dari bentuklahan vulkanis. Kecamatan Windusari memiliki variasi bentuklahan mulai dari kerucut hingga kaki gunungapi. Terdapat empat jenis tanah yang tersebar di daerah penelitian, yaitu Komplek Regosol Kekelabuan dan Litosol, Aluvial Coklat Tua Kekelabuan, Latosol Coklat dan Komplek Latosol Coklat Kemerahan. Penggunaan lahan di Kecamatan Windusari memiliki variasi mulai dari penggunaan lahan untuk semak belukar, rumput, sawah, tegalan, kebun, hutan, serta Pemukiman.

\section{Pengaruh Faktor Bahaya, Kerentanan, dan Kapasitas, dalam Menentukan Risiko Bencana Tanah Longsor}

Tingkat risiko bencana tanah longsor di Kecamatan Windusari diperoleh dari Peta Ancaman Bencana Tanah Longsor Kabupaten Magelang tahun 2014 yang di terbitkan oleh BPBD Kabupaten Magelang. Berdasarkan peta tersebut dapat diperoleh informasi bahwa Kecamatan Windusari dibagi menjadi tiga kategori, yaitu kategori ancaman bencana tanah longsor rendah, kategori ancaman bencana tanah longsor sedang, dan kategori ancaman bencana tanah longsor tinggi (Tabel 1, Gambar 2).

Tabel 1. Luas Wilayah berdasarkan Tingkat Bahaya Tanah Longsor di Kec Windusari

\begin{tabular}{|l|l|c|c|}
\hline No. & Tingkat Bahaya & Luas Wilayah (ha) & Persentase (\%) \\
\hline 1 & Rendah & 1048,955 & 17,01 \\
\hline 2 & Sedang & 2867,764 & 47,18 \\
\hline 3 & Tinggi & 2207,662 & 35,81 \\
\hline \multicolumn{2}{|c|}{ Jumlah } & 6.165 & 100 \\
\hline
\end{tabular}

Sumber: Analisis Data Sekunder, 2016

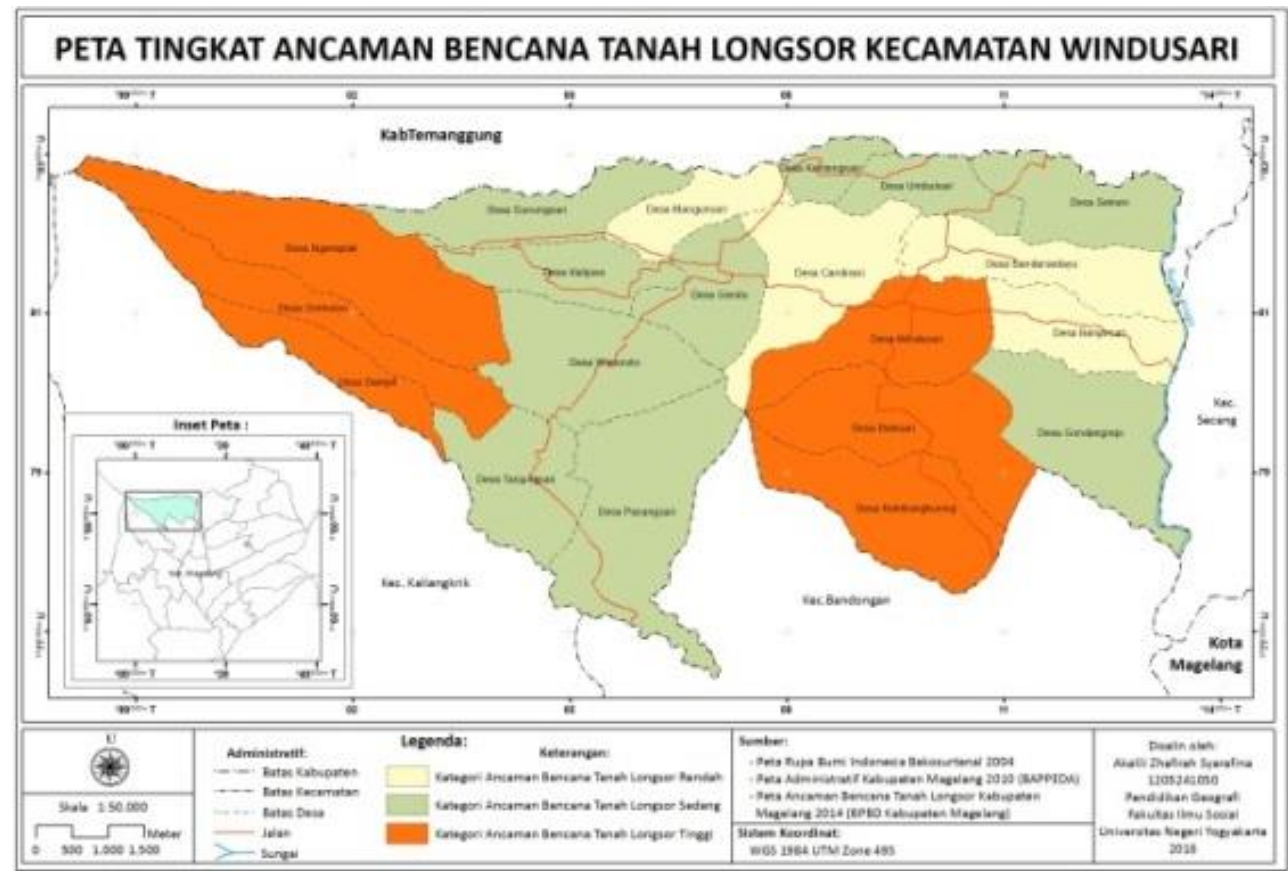

Gambar 2. Peta Tingkat Bahaya Tanah Longsor di Kecamatan Windusari 
Faktor kerentanan terdiri dari kerentanan sosial, ekonomi, fisik dan lingkungan. Semakin besar tingkat kerentanan suatu wilayah, maka berpotensi menimbulkan tingkat risiko yang semakin besar pula pada wilayah tersebut. Terdapat dua kategori tingkat kerentanan di Kecamatan Windusari yaitu tingkat kerentanan tinggi dan sedang. Tingkat kerentanan tinggi lebih banyak dijumpai di Kecamatan Windusari yaitu $55,52 \%$ dari luas wilayah keseluruhan, sedangkan tingkat kerentanan sedang dijumpai pada $44,48 \%$ luas wilayah. Tingkat kerentanan tinggi tersebar di sebagian besar wilayah Kecamatan Windusari. Distribusi tingkat kerentanan di Kecamatan Windusari ditunjukkan oleh Tabel 2 dan Gambar 3.

Tabel 2. Luas Wilayah Terancam menurut Tingkat Kerentanan di Kec. Windusari

\begin{tabular}{|c|c|c|}
\hline Tingkat Kerentanan & $\begin{array}{c}\text { Luas Wilayah } \\
\text { Terancam (ha) }\end{array}$ & $\begin{array}{c}\text { Persentase Luas Wilayah } \\
\text { Terancam (\%) }\end{array}$ \\
\hline Tinggi & 3.423 & 55,52 \\
\hline Sedang & 2.742 & 44,48 \\
\hline Jumlah & 6.165 & 100 \\
\hline
\end{tabular}

Sumber: Analisis Data Sekunder, 2016

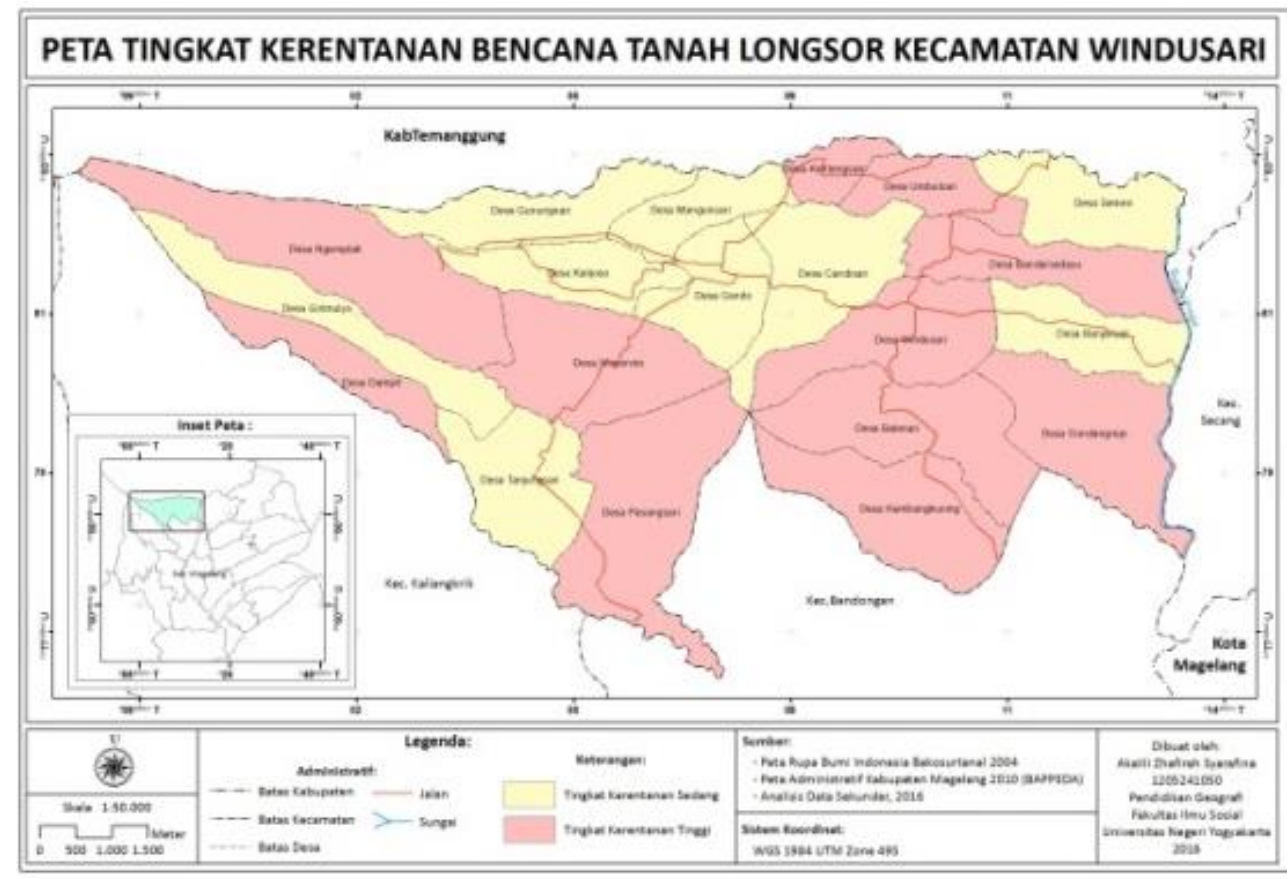

Gambar 3. Peta Tingkat Kerentanan terhadap Bencana Tanah Longsor di Kecamatan Windusari

Faktor Kapasitas terdiri dari organisasi penanggulangan bencana, sistem peringatan dini, pendidikan kebencanaan, pengurangan faktor risiko dasar, kesiapsiagaan pada seluruh lini. Semakin besar tingkat kapasitas suatu wilayah, maka semakin kecil risiko yang mungkin timbul. Hasil penghitungan kapasitas dalam menghadapi bencana di Kecamatan Windusari menunjukkan terdapat tiga kategori kapasitas dalam menghadapi bencana yaitu tinggi sedang dan rendah. Tingkat kapasitas rendah paling banyak dijumpai di Kecamatan 
Windusari dengan area cakupan sebesar $56,87 \%$, diikuti tingkat kapasitas sedang $(32,73 \%)$ dan tinggi (10,49\%). Tingkat kapasitas dalam menghadapi bencana selengkapnya ditunjukkan pada Tabel 3 dan Gambar 4.

Tabel 3. Luas Wilayah Terancam menurut Tingkat Kapasitas di Kec. Windusari

\begin{tabular}{|c|c|c|}
\hline Tingkat Kapasitas & $\begin{array}{c}\text { Luas Wilayah } \\
\text { Terancam (ha) }\end{array}$ & $\begin{array}{c}\text { Persentase Luas Wilayah } \\
\text { Terancam (\%) }\end{array}$ \\
\hline Tinggi & 641 & 10,49 \\
\hline Sedang & 2.018 & 32,73 \\
\hline Rendah & 3.506 & 56,87 \\
\hline Jumlah & 6.165 & 100 \\
\hline
\end{tabular}

Sumber: Analisis Data Sekunder, 2016

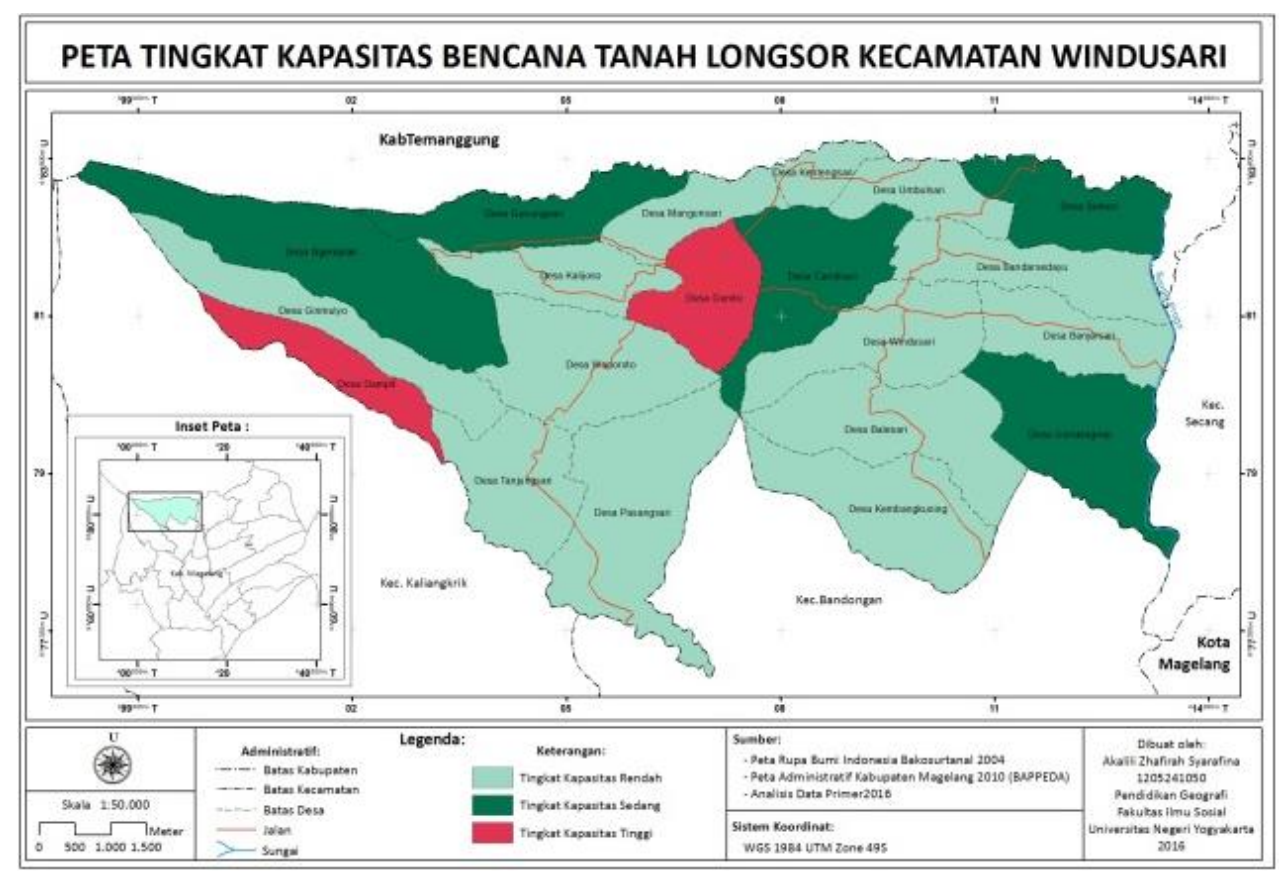

Gambar 4. Peta Tingkat Kapasitas masyarakat terhadap Bencana Tanah Longsor di Kecamatan Windusari

\section{Tingkat Risiko Bencana Tanah Longsor di Kecamatan Windusari}

Berdasarkan hasil penelitian terhadap tiga variabel (bahaya, kerentanan, dan kapasitas) terhadap tingkat risiko bencana tanah longsor di Kecamatan Windusari di peroleh 3 tingkatan risiko bencana tanah longsor, yaitu: tingkat risiko rendah, sedang, dan tinggi. Tingkat risiko tanah longsor diperoleh dari pengolahan data primer dan sekunder dengan cara pemberian harkat. Pemberian harkat disesuaikan dengan tingkat risiko bencana tanah longsor di daerah penelitian. Harkat tertinggi adalah 30 dan harkat terendah adalah 10. Harkat bernilai 30 mempunyai pengaruh yang lebih besar terhadap tingkat risiko bencana tanah longsor, sedangkan harkat 10 memiliki pengaruh yang lebih kecil. Harkat dari variabel bahaya dikalikan dengan variabel kerentanan dan hasilnya dibagi dengan variabel kapasitas. Hasil persamaan tertinggi adalah 90 dan hasil terendah adalah 3,33. 
Variabel bahaya, kerentanan dan kapasitas sebagai faktor yang memengaruhi tingkat risiko bencana tanah longsor memiliki pengaruh yang berbeda-beda pada setiap tingkatan risiko bencana tanah longsor di Kecamatan windusari.

Daerah yang mempunyai tingkat risiko bencana tanah longsor rendah di Kecamatan Windusari terdiri dari tingkat bahaya, tingkat kerentanan, dan tingkat kapasitas yang beragam mulai dari yang terendah hingga tertinggi. Daerah yang memiliki tingkat risiko bencana tanah longsor rendah di kecamatan windusari dapat dilihat pada Tabel 4. Daerah yang mempunyai tingkat risiko bencana tanah longsor rendah memiliki interval nilai hasil persamaan antara 3 hingga 31. Variasi nilai hasil dari persamaan untuk memperoleh nilai risiko terdiri dari: 10; 13,33; 15; dan 20. Risiko bencana tanah longsor rendah memiliki area seluas 3200 ha atau setara dengan 51,91\% dari luas wilayah penelitian.

Tabel 4. Tingkat Risiko Bencana Tanah Longsor Rendah di Kec. Windusari

\begin{tabular}{|l|c|c|c|c|}
\hline \multicolumn{1}{|c|}{ Desa } & Bahaya & Kerentanan & Kapasitas & Risiko \\
\hline Dampit & 30 & 20 & 30 & 20 \\
\hline Tanjungsari & 20 & 10 & 10 & 20 \\
\hline Banjarsari & 10 & 10 & 10 & 10 \\
\hline Bandarsedayu & 10 & 20 & 10 & 20 \\
\hline Candisari & 10 & 30 & 20 & 15 \\
\hline Genito & 20 & 20 & 30 & 13,333 \\
\hline Gunungsari & 20 & 20 & 20 & 20 \\
\hline Mangunsari & 10 & 10 & 10 & 10 \\
\hline Semen & 20 & 10 & 20 & 10 \\
\hline Gondangrejo & 20 & 30 & 20 & 30 \\
\hline
\end{tabular}

Sumber: Analisis Data Primer dan sekunder, 2016

Desa Dampit memiliki skor risiko 20 dan berada pada kriteria rendah. Faktor yang paling berpengaruh terhadap rendahnya tingkat risiko di Desa Dampit ialah faktor kapasitas masyarakat. Tingkat bahaya di Desa Dampit sangat tinggi ditambah dengan faktor kerentanan yang agak tinggi, namun kapasitas masyarakat di Desa Dampit juga tinggi. Kapasitas yang dimiliki Desa Dampit terdiri dari Organisasi Penanggulangan Kebencanaan yaitu Desa Tangguh Bencana yang dibentuk oleh BPBD Kabupaten Magelang, Alat peringatan dini berupa pengeras suara dan peta ancaman bencana tanah longsor, pendidikan kebencanaan berupa sosialisasi dan simulasi, pengurangan faktor risiko dasar yang dilakukan dengan melakukan pembangungan talud, bronjong dan pelestarian kearifan lokal yang berupa gotongroyong, serta kesiapsiagaan pada seluruh lini yang berupa jalur evakuasi, titik kumpul dan barak pengungsian.

Desa Tanjungsari juga memiliki skor risiko 20 pada kriteria rendah. Faktor yang paling berpengaruh terhadap rendahnya tingkat risiko di Desa Tanjungsari ialah faktor tingkat bahaya di Desa Tanjungsari yakni berada pada tingkat sedang dan faktor tingkat kerentanan berada pada tingkat rendah. Faktor kapasitas masyarakat di Desa Tanjungsari 
rendah, ini artinya masyarakat memiliki kapasitas penanggulangan bencana yang kurang baik meskipun faktor bahaya sedang dan kerentanan rendah.

Tingkat risiko di Desa Banjarsari dan Desa Mangunsari termasuk ke dalam kategori risiko rendah dengan skor risiko 10 . Kedua desa tersebut sama-sama memiliki tingkat bahaya, kerentanan dan kapasitas yang rendah, dengan skor masing masing 10. Desa Mangunsari memiliki kerentanan lingkungan yang lebih tinggi dibandingkan dengan Desa Banjarsari, dimana luas hutan di Desa Mangunsari mencapai 43,18 ha sedangkan desa Banjarsari tidak memiliki penggunaan lahan untuk hutan. Desa Bandarsedayu memiliki skor risiko sebesar 20 dan termasuk ke dalam kriteria rendah. Faktor yang paling berpengaruh adalah tingkat bahaya yang rendah. Tingkat kerentanan di Desa Bandarsedayu berada pada tingkat sedangan dan tingkat kapasitas berada pada tingkat rendah.

Desa Candisari memiliki tingkat risiko rendah dengan skor 15. Faktor dominan yang menyebabkan Desa Candisari berada pada tingkat risiko rendah adalah faktor bahaya, dimana faktor bahaya di Desa Candisari. Selain itu faktor tingkat kapasitas yang cukup tinggi menyebabkan tingkat risiko di Desa Candisari menjadi rendah. Desa Genito juga berada pada tingkat risiko rendah dengan skor risiko 13,33. Faktor yang menyebabkan rendah nya tingkat risiko di Desa Genito adalah tingkat kapasitas yang tinggi. Tingkat kapasitas yang tinggi ini disebabkan adanya sistem peringatan dini yang memanfaatkan teknologi tinggi dan di lengkapi sirine. Energi yang di gunakan oleh alat ini memanfaatkan panel surya atau sel surya sehingga tidak terbatas pada pemadaman listrik namun terbatas pada intensitas penyinaran (mendung, kabut dan sebagainya). Faktor bahaya dan kerentanan di Desa Genito berada pada tingkat sedang. Desa Gunungsari memiliki tingkat risiko rendah dengan skor risiko 20. Faktor yang menyebabkan rendah nya tingkat risiko di Desa Gunungsari adalah tingkat bahaya tanah longsor, tingkat kerentanan dan tingkat kapasitas masyarakat berada pada tingkat sedang. Desa semen dan Desa Gondangrejo memiliki tingkat risiko rendah dengan skor 10 dan 30. Kedua desa ini sama-sama memiliki kapasitas masyarakat dalam menghadapi bencana longsor pada tingkat sedang.

Selanjutnya daerah yang mempunyai tingkat risiko bencana tanah longsor sedang di Kecamatan Windusari sebagian besar terdiri dari tingkat bahaya longsor sedang, hanya ada satu yang memiliki tingkat bahaya longsor tinggi. Tingkat kerentanan pada daerah yang mempunyai tingkat risiko bencana tanah longsor sedang di Kecamatan Windusari terdiri dari tingkat sedang hingga tinggi. Kapasitas masyarakat dalam menghadapi bencana tanah longsor pada daerah yang memiliki risiko bencana tanah longsor sedang terdiri dari kapasitas rendah hingga sedang. Tingkat risiko bencana tanah longsor sedang di kecamatan windusari dapat dilihat pada Tabel 5.

Daerah yang mempunyai tingkat risiko bencana tanah longsor sedang memiliki interval nilai hasil persamaan antara 32 hingga 60. Risiko bencana tanah longsor sedang memiliki area seluas 1.845 ha atau setara dengan 29,93\% dari luas keseluruhan. Variasi nilai hasil dari persamaan untuk memperoleh nilai risiko mulai dari: 40, 45 dan 60. Desa dengan risiko bencana tanah longsor sedang tersebar di sepuluh desa di Kecamatan Windusari yaitu Desa Pasangsari, Wonoroto, Girimulyo, Ngemplak, Kalijoso, Kentengsari dan Umbulsari. 
Tabel 5. Tingkat Risiko Bencana Tanah Longsor Sedang di Kecamatan Windusari

\begin{tabular}{|l|c|c|c|c|}
\hline \multicolumn{1}{|c|}{ Desa } & Bahaya & Kerentanan & Kapasitas & Risiko \\
\hline Pasangsari & 20 & 30 & 10 & 60 \\
\hline Wonoroto & 20 & 30 & 10 & 60 \\
\hline Girimulyo & 30 & 20 & 10 & 60 \\
\hline Ngemplak & 30 & 30 & 20 & 45 \\
\hline Kalijoso & 20 & 20 & 10 & 40 \\
\hline Kentengsari & 20 & 20 & 10 & 40 \\
\hline Umbulsari & 20 & 20 & 10 & 40 \\
\hline
\end{tabular}

Sumber: Analisis Data Primer dan sekunder, 2016

Desa Pasangsari dan Desa Wonoroto memiliki tingkat risiko sedang dengan skor 60, angka ini hampir menuju pada tingkat risiko tinggi dimana batas minimalnya 61. Tingkat bahaya, kerentanan, dan kapasitas masyarakatnya di kedua desa ini memiliki tingkatan yang sama. Faktor yang paling berpengaruh terhadap tingkat risiko sedang di kedua desa ini adalah faktor kerentanan yang tinggi dan faktor kapasitas yang rendah. Faktor bahaya di kedua desa ini berada pada tingkat sedang. Desa Pasangsari memiliki selisih tingkat kapasitas yang sedikit lebih tinggi dibandingkan dengan desa Wonoroto. Meskipun sama sama memiliki tingkat kapasitas rendah namun Desa Pasangsari memiliki skor 14 dan desa wonoroto memiliki skor kerentanan total 10. Hal tersebut disebabkan oleh Desa Pasangsari unggul dalam Pendidikan Kebencanaan dimana pernah dilakukan penyuluhan dan simulasi kebencanaan. Desa Girimulyo tidak jauh berbeda dengan Desa Pasangsari dan Desa Wonoroto, desa ini juga memiliki skor risiko 60. Perbedaann terletak pada tingkat bahaya yang tinggi dengan kerentanan sedang, namun sama-sama memiliki kapasitas yang rendah. Desa Girimulyo memiliki kerentanan sedang yang disebabkan oleh kerentanan fisik yang sedikit lebih rendah dibandingkan Desa Pasangsari dan Desa Wonoroto.

Desa Ngemplak memiliki sedikit kesamaan dengan Desa Girimulyo, yaitu merupakan dua desa dengan tingkat bahaya tertinggi pada kriteria risiko sedang. Desa Ngemplak memiliki skor risiko 45 dan merupakan satu-satunya yang memiliki skor tersebut. Faktor yang paling berpengaruh terhadap tingkat risiko sedang di Desa Ngemplak ialah faktor kapasitas masyarakat yang berada pada tingkat sedang. Desa Ngemplak memiliki tingkat bahaya dan tingkat kerentanan tinggi namun memiliki kapasitas sedang, sehingga mampu menekan tingkat bahaya dan tingkat kerentanan.

Desa Kalijoso, Kentengsari dan Umbulsari memiliki skor risiko 40 dan termasuk ke dalam kriteria sedang. Ketiga desa ini sama-sama memiliki bahaya dan kerentanan pada tingkat sedang, serta kapasitas masyarakat pada tingkat rendah. Perbedaannya terletak pada kerentanan fisik Desa Kalijoso yang lebih rendah dibandikan Desa Kentengsari dan Umbulsari, dimana Desa Kalijoso memiliki tingkat kerentanan fisik rumah yang rendah sedangkan Desa Kentengsari dan Umbulsari berada pada tingkat kerentanan fisik rumah sedang. 
Selanjutnya daerah yang mempunyai tingkat risiko bencana tanah longsor tinggi di Kecamatan Windusari sebagian besar terdiri dari tingkat bahaya longsor tinggi. Tingkat kerentanan pada daerah yang mempunyai tingkat risiko bencana tanah longsor tinggi di Kecamatan Windusari terdiri dari tingkat tinggi. Kapasitas masyarakat dalam menghadapi bencana tanah longsor pada daerah yang memiliki risiko bencana tanah longsor tinggi terdiri dari kapasitas rendah (Tabel 6).

Tabel 6. Tingkat Risiko Bencana Tanah Longsor Tinggi di Kecamatan Windusari

\begin{tabular}{|l|c|c|c|c|}
\hline \multicolumn{1}{|c|}{ Desa } & Bahaya & Kerentanan & Kapasitas & Risiko \\
\hline Kembangkuning & 30 & 30 & 10 & 90 \\
\hline Balesari & 30 & 30 & 10 & 90 \\
\hline Windusari & 30 & 30 & 10 & 90 \\
\hline
\end{tabular}

Sumber: Analisis Data Primer dan sekunder, 2016

Daerah yang mempunyai tingkat risiko bencana tanah longsor tinggi memiliki interval nilai hasil persamaan antara 61 hingga 90. Risiko bencana tanah longsor tinggi memiliki area seluas 1.120 ha atau setara dengan $18,16 \%$ dari luas keseluruhan. Tidak terdapat variasi skor hasil persamaan untuk memperoleh nilai risiko, skor risiko seragam pada angka 90 yang juga merupakan angka tertinggi. Desa dengan risiko bencana tanah longsor tinggi tersebar di tiga desa di Kecamatan Windusari yaitu Desa Kembangkuning, Balesari dan Windusari.

Desa Kembangkuning, Balesari dan Windusari merupakan tiga desa di Kecamatan Windusari dengan risiko tertinggi. Faktor yang paling berpengaruh terhadap tingginya tingkat risiko di ketiga desa ini adalah faktor bahaya dan kerentanan yang tinggi, serta kapasitas masyarakat yang rendah. Terdapat perbedaan pada faktor kerentanan yang tidak terlalu mencolok, yaitu pada kerentanan lingkungan. Desa Windusari tidak memiliki penggunaan lahan untuk hutan, sedangkan Desa Balesari memiliki luas penggunaan lahan untuk hutan tertinggi di Kecamatan Windusari yang mencapai angka 278,72 ha. Desa Kembangkuning memiliki kerentanan lingkungan berupa hutan yang juga tinggi dimana mencapai angka 72,97 ha.

Kapasitas masyarakat di Desa Kembangkuning, Balesari dan Windusari termasuk dalam kategori rendah. Ketiga desa ini tidak memiliki organisasi penanggulangan bencana, meskipun memiliki tingkat bahaya bencana tanah longsor yang tinggi. Pada faktor sistem peringatan dini, Desa Kembangkuning memiliki keunggulan dimana desa ini menerapkan teknologi sederhana untuk peringatan terhadap bencana tanah longsor. Teknologi sederhana ini berupa benang yang di ikat pada dua tiang pancang yang di tancapkan pada lereng-lereng, jika benang ini putus maka pada daerah tersebut memiliki potensi gerakan tanah dan warga harus bersiap jika sewaktu-waktu terjadi bencana tanah longsor. Penggunaan alat pengeras suara yang terdapat pada masjid juga digunakan sebagai EWS pada ketiga desa ini.

Pendidikan kebencanaan baru dilakukan oleh Desa Windusari dalam bentuk sosialiasi, kedua desa lainnya belum melakukan pendidikan kebencanaan. Pengurangan 
faktor risiko bencana telah dilakukan dengan pembangunan talud di desa Balesari dan Windusari, pengurangan faktor risiko bencana belum dilakukan oleh Desa Kembangkuning. Kesamaan lainnya adalah dengan tidak dijumpai bangunan kesiapsiagaan pada ketiga desa ini.

\section{Sebaran Daerah Dengan Risiko Bencana Longsor di Kecamatan Windusari}

Daerah dengan risiko bencana tanah longsor tersebar di seluruh wilayah penelitian. Setiap daerah memiliki luas yang bervariasi dan dipengaruhi oleh faktor bahaya, kerentanan, dan kapasitas dengan kadar yang beragam. Sebaran daerah berisiko bencana tanah longsor di Kecamatan Windusari disusun berdasarkan tingkat risiko bencana tanah longsor.

Wilayah dengan risiko bencana tanah longsor rendah tersebar seluas 3.200 ha atau setara dengan $51,91 \%$ dari luas wilayah penelitian. Desa dengan risiko bencana tanah longsor rendah tersebar di sepuluh desa di Kecamatan Windusari yaitu Desa Dampit, Tanjungsari, Banjarsari, Bandarsedayu, Candisari, Genito, Gunungsari, Mangunsari, Semen, dan Gondangrejo. Sebaran daerah dengan risiko bencana tanah longsor rendah tiap desa di Kecamatan Windusari dapat dilihat pada Tabel 7.

Tabel 7. Sebaran Daerah dengan Risiko Bencana Tanah Longsor Rendah di Kec. Windusari

\begin{tabular}{|c|c|c|}
\hline Desa & Luas (ha) & Persentase (\%) \\
\hline Dampit & 218 & 6,81 \\
\hline Tanjungsari & 323 & 10,09 \\
\hline Banjarsari & 227 & 7,09 \\
\hline Bandarsedayu & 236 & 7,38 \\
\hline Candisari & 570 & 17,81 \\
\hline Genito & 423 & 13,22 \\
\hline Gunungsari & 388 & 12,13 \\
\hline Mangunsari & 117 & 3,66 \\
\hline Semen & 209 & 6,53 \\
\hline Gondangrejo & 489 & 15,28 \\
\hline Jumlah & 3.200 & 100 \\
\hline Rata-rata & 320 & \\
\hline
\end{tabular}

Sumber: Analisis Data Primer dan sekunder, 2016

Desa terluas pada sebaran daerah dengan risiko bencana tanah longsor rendah di Kecamatan Windusari adalah Desa Candisari dengan luas wilayah 570 ha atau setara dengan $17,81 \%$. Daerah tersempit pada sebaran daerah dengan risiko bencana tanah longsor rendah di Kecamatan Windusari adalah Desa Dampit dengan luas wilayah 218 ha (6,81\%). Rerata luas daerah sebaran risiko bencana tanah longsor rendah adalah 320 ha.

Wilayah dengan risiko bencana tanah longsor sedang tersebar seluas 1.845 ha atau setara dengan $29,93 \%$ dari luas wilayah penelitian. Desa dengan risiko bencana tanah 
longsor sedang tersebar di tujuh desa di Kecamatan Windusari yaitu Desa Pasangsari, Wonoroto, Girimulyo, Ngemplak, Kalijoso, Kentengsari dan Umbulsari. Rincian sebaran daerah dengan risiko bencana tanah longsor sedang masing-masing desa di Kecamatan Windusari dapat dilihat pada Tabel 8.

Tabel 8. Sebaran Daerah dengan Risiko Bencana Tanah Longsor Sedang di Kec. Windusari

\begin{tabular}{|l|c|c|}
\hline \multicolumn{1}{|c|}{ Desa } & Luas (ha) & Persentase (\%) \\
\hline Pasangsari & 404 & 21,90 \\
\hline Wonoroto & 358 & 19,40 \\
\hline Girimulyo & 324 & 17,56 \\
\hline Ngemplak & 362 & 19,62 \\
\hline Kalijoso & 161 & 8,73 \\
\hline Kentengsari & 90 & 4,88 \\
\hline Umbulsari & 146 & 7,91 \\
\hline \multicolumn{1}{|c|}{ Jumlah } & 1.845 & 100 \\
\hline Rata-rata & 263,57 & \\
\hline
\end{tabular}

Sumber: Analisis Data Primer dan sekunder, 2016

Desa terluas pada sebaran daerah dengan risiko bencana tanah longsor sedang di Kecamatan Windusari adalah Desa Pasangsari dengan luas wilayah 404 ha atau setara dengan 21,9\%. Daerah tersempit pada sebaran daerah dengan risiko bencana tanah longsor sedang di Kecamatan Windusari adalah Desa Kentengsari dengan luas wilayah 90 ha atau setara dengan 4,88\%. Rata-rata luas daerah sebaran risiko bencana tanah longsor sedang adalah 263,57 ha.

Wilayah dengan risiko bencana tanah longsor tinggi tersebar seluas 1.120 ha atau setara dengan $18,16 \%$ dari luas wilayah penelitian. Desa dengan risiko bencana tanah longsor tinggi tersebar di tiga desa di Kecamatan Windusari yaitu Desa Kembangkuning, Balesari dan Windusari. Rincian sebaran daerah dengan risiko bencana tanah longsor tinggi tiap desa di Kecamatan Windusari dapat dilihat pada Tabel 9.

Tabel 9. Sebaran Daerah dengan Risiko Bencana Tanah Longsor Tinggi di Kec Windusari

\begin{tabular}{|l|c|c|}
\hline \multicolumn{1}{|c|}{ Desa } & Luas (ha) & Persentase (\%) \\
\hline Kembangkuning & 350 & 31,25 \\
\hline Balesari & 355 & 31,7 \\
\hline Windusari & 415 & 37,05 \\
\hline \multicolumn{1}{|c|}{ Jumlah } & 1.120 & 100 \\
\hline
\end{tabular}

Sumber: Analisis Data Primer dan sekunder, 2016

Desa terluas pada sebaran daerah dengan risiko bencana tanah longsor tinggi di Kecamatan Windusari adalah Desa Windusari dengan luas wilayah 404 ha atau setara dengan $21,9 \%$. Daerah tersempit pada sebaran daerah dengan risiko bencana tanah 
longsor tinggi di Kecamatan Windusari adalah Desa Kembangkuning dengan luas wilayah 350 ha atau setara dengan $31,25 \%$. Rata-rata luas daerah sebaran risiko bencana tanah longsor tinggi adalah 373,33 ha.

Tingkat risiko diperoleh dari hasil overlay antara peta ancaman bahaya, kerentanan dan kapasitas. Risiko terhadap bencana tanah longsor di Kecamatan Windusari terdiri dari tiga tingkat risiko, yaitu risiko rendah, sedang dan tinggi. Semakin tinggi tingkat risiko maka kemungkinan kerugian akibat bencana tanah longsor semakin besar. Potensi kerugian tersebut dapat berupa hilangnya harta benda, korban luka, korban sakit, korban hilang, korban terancan, hingga korban jiwa. Kerugian yang mungkin timbul dapat menurun seiring dengan tingginya kapasitas penanggulangan bencana di suatu wilayah. Tingkat risiko bencana tanah longsor di Kecamatan Windusari ditunjukkan oleh Tabel 10 dan Gambar 5

Tabel 10. Luas Wilayah Terancam menurut Tingkat Risiko di Kecamatan Windusari

\begin{tabular}{|c|c|c|}
\hline Tingkat Risiko & Luas Wilayah Terancam (ha) & $\begin{array}{c}\text { Persentase Luas Wilayah } \\
\text { Terancam (\%) }\end{array}$ \\
\hline Tinggi & 1.120 & 18,87 \\
\hline Sedang & 1.845 & 29,93 \\
\hline Rendah & 3.200 & 51,91 \\
\hline Jumlah & 6.165 & 100 \\
\hline
\end{tabular}

Sumber: Analisis Data Sekunder, 2016

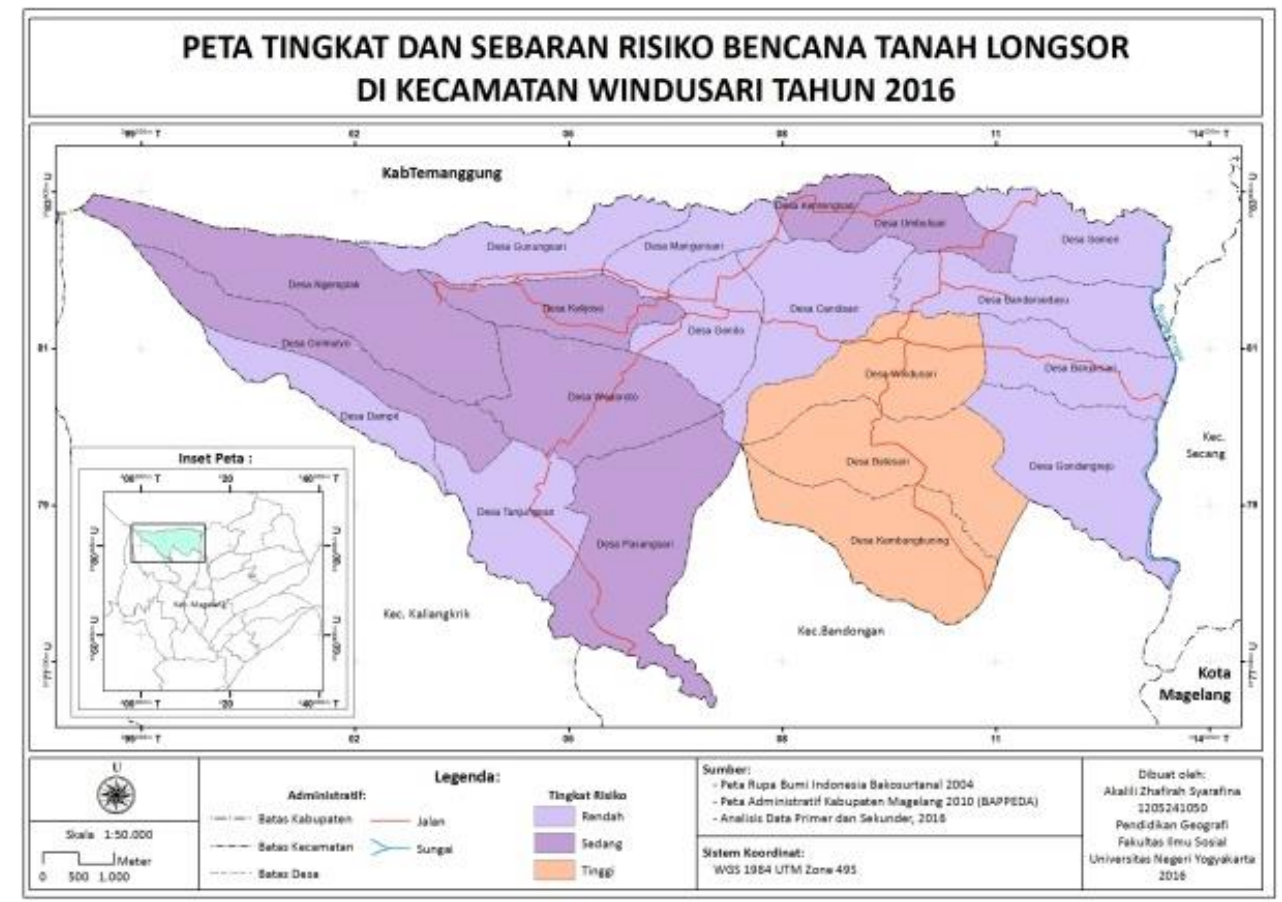

Gambar 5. Peta Persebaran Tingkat Risiko Bencana Tanah Longsor di Kecamatan Windusari 


\section{SIMPULAN}

Tingkat risiko bencana tanah longsor di Kecamatan Windusari yang dipengaruhi oleh faktor bahaya, kerentanan dan kapasitas terdiri dari tiga tingkat yaitu tingkat risiko bencana tanah longsor rendah, sedang dan tinggi. Semakin tinggi tingkat risiko bencana maka potensi kerugian akibat terjadinya bencana (korban luka, korban jiwa, sakit, mengungsi, kehilangan rasa aman, kehilangan harta benda, rusaknya fasilitas umum serta kerusakan lahan pertanian) akan semakin tinggi. Tingkat risiko bencana tanah longsor rendah tersebar seluas 3.200 ha. Tingkat risiko bencana tanah longsor sedang tersebar seluas 1.845 ha. Tingkat risiko bencana tanah longsor tinggi tersebar seluas 1.120 ha. Tingkat risiko yang bervariasi dipengaruhi oleh faktor bahaya, kerentanan, dan kapasitas sebagai faktor penentu risiko yang kondisinya juga bervariasi.

\section{UCAPAN TERIMA KASIH}

Tulisan ini asalah bagiann dari tugas akhir skripsi yang berjudul Tingkat dan Sebaran Risiko Bencana Tanah Longsor berdasarkan Pengharkatan di Kecamatan Windusari Kabupaten Magelang. Dalam kesempatan ini penulis mengucapkan terima kasih kepada seluruh pihak yang telah membantu selama pelaksanaan penelitian, khususnya kepada pembimbing tugas akhir.

\section{DAFTAR PUSTAKA}

Hardiyatmo, H.C. 2006. Tanah Longsor dan Erosi: Kejadian dan Penanganan. Yogyakarta: Gajah Mada University Press.

Peta Ancaman Bencana Tanah Longsor Kabupaten Magelang Tahun 2014 diterbitkan oleh Badan Penanggulangan Bencana Daerah Magelang.

Thanden, R. E. et al. 1996. Peta Geologi Lembar Magelang dan Semarang, Jawa. Bandung: Pusat Survei Geologi.

Van Bemmelen, R.W. 1949. The Geology of Indonesia volume IA General Geology of Indonesia and Adjacent Archipelagoes. Belanda: Goverment Printing Office, The Hague. 